ORGANIZATION AND FUNCTIONS

\title{
UNITED \\ STATES ARMY \\ DRUG AND \\ ALCOHOL \\ TECHNICAL \\ ACTIVITY
}




\begin{tabular}{|c|c|}
\hline \multicolumn{2}{|c|}{ Report Documentation Page } \\
\hline $\begin{array}{l}\text { Report Type } \\
\text { N/A }\end{array}$ & Dates Covered (from... to) \\
\hline \multirow{3}{*}{$\begin{array}{l}\text { Title and Subtitle } \\
\text { Organization and Functions: United States Army Drug } \\
\text { and Alcohol Technical Activity }\end{array}$} & Contract Number \\
\hline & Grant Number \\
\hline & Program Element Number \\
\hline \multirow[t]{3}{*}{ Author(s) } & Project Number \\
\hline & Task Number \\
\hline & Work Unit Number \\
\hline $\begin{array}{l}\text { Performing Organization Name(s) and Address(es) } \\
\text { Department of the Army Headquarters Washington, DC }\end{array}$ & Performing Organization Report Number \\
\hline \multirow{2}{*}{$\begin{array}{l}\text { Sponsoring/Monitoring Agency Name(s) and } \\
\text { Address(es) }\end{array}$} & Sponsor/Monitor's Acronym(s) \\
\hline & Sponsor/Monitor's Report Number(s) \\
\hline \multicolumn{2}{|l|}{$\begin{array}{l}\text { Distribution/Availability Statement } \\
\text { Approved for public release, distribution unlimited }\end{array}$} \\
\hline \multicolumn{2}{|l|}{ Supplementary Notes } \\
\hline \multicolumn{2}{|l|}{ Abstract } \\
\hline \multicolumn{2}{|l|}{ Subject Terms } \\
\hline $\begin{array}{l}\text { Report Classification } \\
\text { unclassified }\end{array}$ & $\begin{array}{l}\text { Classification of this page } \\
\text { unclassified }\end{array}$ \\
\hline $\begin{array}{l}\text { Classification of Abstract } \\
\text { unclassified }\end{array}$ & $\begin{array}{l}\text { Limitation of Abstract } \\
\text { UU }\end{array}$ \\
\hline $\begin{array}{l}\text { Number of Pages } \\
8\end{array}$ & \\
\hline
\end{tabular}




\section{SUMMARY of CHANGE}

AR $10-78$

UNITED STATES ARMY DRUG AND ALCOHOL TECHNICAL ACTIVITY

Not applicable.

$\bigcirc$

$\bigcirc$ 


\section{ORGANIZATION AND FUNCTIONS}

\section{UNITED STATES ARMY DRUG AND ALCOHOL TECHNICAL ACTIVITY}

By Order of the Secretary of the Army
E. C. MEYER
General, United States Army
Chief of Staff
Official:
ROBERT M. JOYCE
Major General, United States Army
The Adjutant General

History. This publication has been reorganized to make it compatible with the Army electronic publishing database. No content has been changed.

Summary. This revision changes the title of the Commander of the US Army
Drug and Alcohol Technical Activity to Director; it also outlines new mission and principal functions of the US Army Drug and Alcohol Technical Activity.

Applicability. This regulation applies to the Active Army, the Army National Guard, and the US Army Reserve.

Proponent and exception authority. The proponent agency of this regulation is the Office of the Deputy Chief of Staff for Personnel.

Army management control process. Not applicable.

Supplementation. Local supplementation of this regulation is prohibited, except upon approval of the Deputy Chief of Staff for Personnel. Send requests for exception, with justification, through command channels, to HQDA (DAPE-HRA), WASH DC 20310.

Interim changes. Interim changes to this regulation are not official unless they are authenticated by The Adjutant General. Users will destroy interim changes on their expiration dates unless sooner superseded or rescinded.

Suggested Improvements. Users are invited to send comments and suggested improvements on DA Form 2028 (Recommended Change to Publications and Blank Forms) directly to HQDA(DAPE-HRA), WASH DC 20310.

Distribution. Active Army, ARNG, USAR: To be distributed in accordance with DA Form 12-9A requirements for AR, Organization and Functions-D.

Contents (Listed by paragraph and page number)

Purpose. - 1, page 1

Applicability. - 2, page 1

Mission. - 3, page 1

Functions. - 4, page 1

Command and staff relationships. - 5, page 2

Channels of communication. $\cdot 6$, page 2 


\section{RESERVED}

AR 10-78 • 1 October 1982 


\section{Purpose.}

This regulation-

a. Sets forth the mission and functions of the Director, US Army Drug and Alcohol Technical Activity (USADATA).

$b$. Prescribes channels of communication and command and staff relationships with HQDA agencies and other Army elements.

\section{Applicability.}

This regulation applies to the Active Army, National Guard, and the US Army Reserve.

\section{Mission.}

The mission of the Director, USADATA, is to support combat effectiveness by providing centralized management of the Alcohol and Drug Abuse Prevention and Control Program (ADAPCP), under AR 600-85. This includes the following:

a. Field support.

$b$. Public affairs support.

c. Overall program operation and management.

$d$. Planning analysis and evaluation.

e. Resource management.

\section{Functions.}

The functions of the Director, USADATA, are shown below.

a. Field support. The Director, USADATA, provides Army commanders with technical support and assistance in all aspects of the Army ADAPCP, under DA Pam 600-85. This support is shown below. Technical support to ADAPCP clinical activities in the field is provided by Army Medical Department personnel assigned to USADATA.

(1) Consultation designed to improve program operation and management in areas such as the following:

(a) Counseling.

(b) Residential treatment programs.

(c) Prevention and education.

(d) Civilian aspects (including family life).

(e) Management information systems.

(f) Program evaluation.

(g) Resource management (budget formulation and manpower).

(2) Education and training assistance designed to make commanders, supervisors, and other groups aware of all aspects of the ADAPCP and the problems connected with alcohol and other drug abuse. Assistance includes the following:

(a) Providing resource information.

(b) Developing programs.

(c) Conducting training workshops.

(d) Presenting specialized programs for instructors.

(3) Assisting commanders and supervisors Army-wide to implement periodic ADAPCP changes and establish internal evaluation procedures.

b. Public affairs support. The Director, USADATA, provides public affairs support by the following:

(1) Facilitating communication between commanders and supervisors in the field and HQDA in their ongoing efforts to prevent and control alcohol and other drug abuse.

(2) Disseminating information about the ADAPCP and alcohol and other drug abuse in general to the field through appropriate Army publications and public awareness programs.

c. Program operation and management. The Director, USADATA, will exercise day-to-day operational supervision of the ADAPCP. The USADATA Director also will monitor execution of Army ADAPCP policy, goals, and objectives worldwide. These programs include the following:

(1) Providing direct support for the Army Staff by formulating recommendations to be used as the basis for decisions by the proponent Army Staff element.

(2) Implementing policy, plans, and procedures for ADAPCP worldwide in response to established policies and objectives.

(3) Developing requirements and monitoring alcohol and other drug abuse prevention education and training at all levels for military and DA civilian employees, family members, and ADAPCP staff.

(4) Providing operational supervision of the DOD urinalysis program for the Army; collecting, analyzing, and disseminating alcohol and other drug abuse identification information and statistics. 
(5) Monitoring ADAPCP manpower utilization, tables of authorization and staffing guides, overall program management, and effectiveness and quality of services provided.

(6) Managing civilian aspects of the ADAPCP. This includes providing input for policy regarding ADAPCP services for DA civilian employees, family members, and military retirees worldwide.

(7) Resolving day-to-day problems of major Army command (MACOM) and installation ADAPCP personnel.

(8) Performing other functions, as directed, to prevent and control alcohol and other drug abuse Army-wide.

d. Planning, analysis, and evaluation. The Director, USADATA, will evaluate overall ADAPCP effectiveness and assess the impact of alcohol and other drug abuse in the Army. These functions include the following:

(1) Conducting on-site program evaluations. Providing process observations and evaluation of the ADAPCP, offering feedback to assist in mission accomplishment. Program evaluations are conducted upon request of field commanders, in conjunction with MACOM assistance visits, or as directed by the Deputy Chief of Staff for Personnel (DCSPER).

(2) Assisting in collecting data for Army-wide studies related to alcohol and other drug abuse.

(3) Evaluating program effectiveness through on-site visits and communication with MACOMs, monitoring trends through management information systems, and reviewing input from the field.

(4) Directing and operating the ADMCP automated, multi-sourced management information system; providing comprehensive reports to the Army Staff, MACOM commanders, and DOD.

(5) Providing Alcohol and Drug Policy Office (HQDA (DAPE-HRA)) analysis of detail data collected for development of program policy and objectives.

(6) Providing supervision of alcohol and other drug abuse research and studies initiated by the Office of the DCSPER (ODCSPER); preparing requests for proposals as required, supervising contracts, and providing funding as necessary, within USADATA resources.

e. Resource management. The Director, USADATA, will-

(1) Formulate and execute the USADATA budget.

(2) Provide input for the overall ADAPCP budget.

(3) Provide programmatic manpower and budget analyses for determining initial needs.

(4) Maintain staffing inventory data for the worldwide ADAPCP program.

\section{Command and staff relationships.}

USADATA is a field, operating agency of the DCSPER, HQDA. USADATA is under the staff supervision of the Alcohol and Drug Policy Office (DAPE-HRA), Human Resources Development Directorate, ODCSPER.

\section{Channels of communication.}

a. The Director, USADATA, may communicate directly with HQDA agencies and the field as required for the following:

(1) Responding to requests for information.

(2) Responding to requests for assistance.

(3) Providing information on services offered.

(4) Scheduling and making logistical arrangements for visits.

$b$. Questions from the field on program operation or management should be directed to Director, USADATA, NASSIF Bldg., Room 323, Falls Church, VA 22041, or AUTOVON numbers 289-24531/4. 


\section{UNCLASSIFIED}

PIN 04745-900 


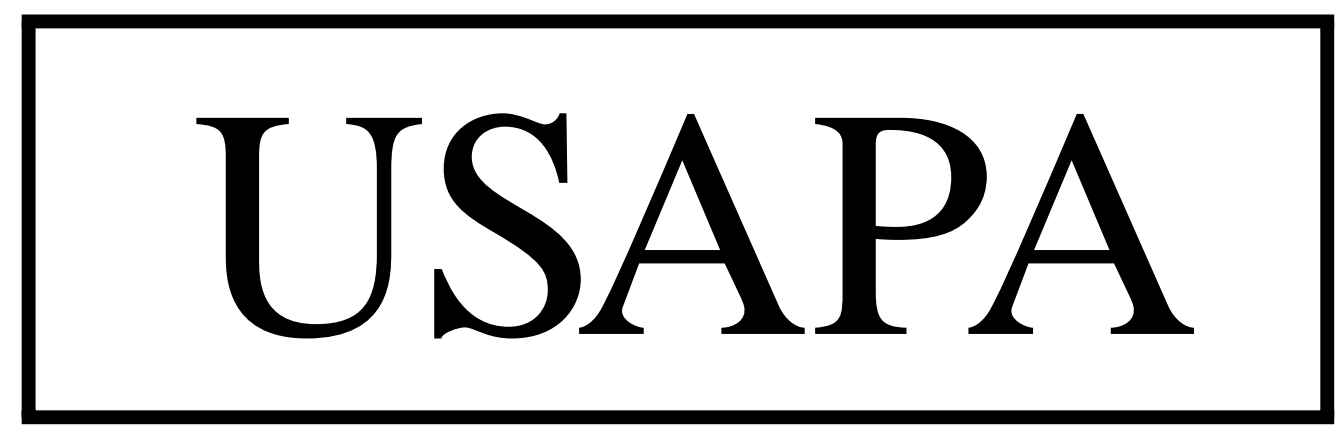

ELECTRONIC PUBLISHING SYSTEM

OneCol FORMATTER .WIN32 Version 137

PIN:

04745-900

DATE:

01-30-01

TIME:

09:28:03

PAGES SET: 6

DATA FILE: C:Iwincomplyonatan.fil

DOCUMENT: AR 10-78

DOC STATUS: NEW PUBLICATION 